\title{
Can readmissions be reduced after retrograde intrarenal surgery for renal stone?
}

\author{
Mustafa Karaaslan $^{1}$ (I) . Yusuf Kasap ${ }^{1}$
}

Received: 30 October 2019 / Accepted: 5 November 2019 / Published online: 16 November 2019

c) Springer-Verlag GmbH Germany, part of Springer Nature 2019

We read the article 'Analysis of factors affecting readmission after retrograde intrarenal surgery for renal stone' by Kim et al. [1] with great interest. In this study, the post RIRS readmission was observed as $3.5 \%$, which was quite low. This may be due to the high rate of preoperative ureteral stenting and low ASA score. The most of readmission patients had ureteral stent insertion during readmission. Postoperative ureteral stent was applied at a very high rate of $98.5 \%$. Routine ureteral stent placement increases postoperative morbidity for patients. This likely are related to both mechanical irritations from the stent and increased urinary tract pressures transmitted through reflux [2]. Routine stent placement is not necessary in uncomplicated endoscopic procedures. In iatrogenic ureteral injuries, stenosis cases and large residual stone load, and ureteral stent placement should be considered [3]. In a study, morbidity after RIRS was higher in patients who underwent postoperative ureteral stenting [4].
We find the study valuable and we believe that the readmission rate can be reduced by placing a ureteral stent postoperatively in selected cases.

\section{References}

1. Kim TJ et al (2019) Analysis of factors affecting re-admission after retrograde intrarenal surgery for renal stone. World J Urol 37(6):1205-1210

2. Fischer KM, Louie M, Mucksavage P (2018) Ureteral stent discomfort and its management. Curr Urol Rep 19(8):64

3. Byrne RR et al (2002) Routine ureteral stenting is not necessary after ureteroscopy and ureteropyeloscopy: a randomized trial. J Endourol 16(1):9-13

4. Ozyuvali E et al (2015) Is routine ureteral stenting really necessary after retrograde intrarenal surgery? Archivio Italiano di Urologia e Andrologia 87(1):72-75

Publisher's Note Springer Nature remains neutral with regard to jurisdictional claims in published maps and institutional affiliations.

This comment refers to the article available online at https://doi. org/10.1007/s00345-018-2507-0.

Mustafa Karaaslan

mustafakaraaslan23@gmail.com

1 Department of Urology, Ankara City Hospital, Ankara, Turkey 